Palavras chave:

Cedro australiano

Constituintes químicos

Retratibilidade

Histórico:

Recebido 16/08/20 I I

Aceito 04/10/2013

Keywords:

Australian cedar

Chemical

Shrinkage

Correspondência: rafaelfarinassi@gmail.com
Alessandra de Oliveira Ribeiro', Rafael Farinassi Mendes', Lourival Marin Mendes', Fábio Akira Mori', Raiana Quirino de Souza Ziech'

\section{RETRATIBILIDADE DA MADEIRA DE Toona ciliata M. ROEM PROVENIENTE DE TRÊS MUNICÍPIOS DO SUL DE MINAS GERAIS}

RESUMO: Neste trabalho, objetivou-se avaliar a retratibilidade, nos sentidos base-topo e medula-casca, da madeira do Cedro australiano proveniente de três municípios do Sul do estado de Minas Gerais, além ainda de verificar a variação na constituição química da madeira, em decorrência da localidade de plantio. A madeira de Cedro australiano foi obtida com quatro anos de idade e em três municípios da região sul do estado de Minas Gerais (Campo Belo, Cana Verde e Santo Antônio do Amparo). Foram determinados os constituintes químicos da madeira, os valores de retratibilidade (tangencial, radial, longitudinal e volumétrica) e o coeficiente de anisotropia. De acordo com os resultados, conclui-se que não houve variação significativa dos teores de holocelulose, lignina, extrativos e cinzas, entre as três localidades de plantios avaliadas. Para as retratibilidades da madeira no sentido base-topo, não houve variação significativa das contrações radial e longitudinal para as três localidades avaliadas. Contudo, foi observada variação significativa para as contrações tangencial e volumétrica para as localidades de Campo Belo e Cana Verde, e variação significativa da contração tangencial para o plantio de Santo Antonio do Amparo. Na direção medula-casca, foi observada variação significativa apenas da contração radial e do coeficiente de anisotropia para a localidade de Cana Verde.

\section{SHRINKAGE OF THE Toona ciliata WOOD FROM THREE COUNTIES IN THE SOUTH OF MINAS GERAIS STATE}

ABSTRACT: The study aimed to evaluate the shrinkage, in the bottom-up and pith-bark direction, of the australian cedar wood from three Counties in the south of Minas Gerais state, and also to check the variation in chemical composition of wood due the location of planting. The australian cedar wood was obtained with four years of age and in three cities in the south of Minas Gerais state (Campo Belo, Cana Verde and Santo Antonio do Amparo). The chemical constituents of wood, shrinkage values (tangential, radial, longitudinal and volumetric) and the anisotropy coefficient. According to the results, there was no significant variation in the levels of holocellulose were determined, lignin, extractives and ashes between the three plantation sites evaluated. For the shrinkage of the wood in the bottom-up direction, there was no significant variation of the radial and longitudinal contractions for the three locations evaluated. However, significant variation was observed for the tangential and volumetric contractions for cities of Campo Belo and Cana Verde, and significant variation of Tangential contraction for the plantation of Santo Antonio do Amparo. In the pith-bark direction, significant variation was observed only on the radial contraction and the coefficient of anisotropy for location of Cana Verde.
DOI:
' Universidade Federal de Lavras - Lavras, Minas Gerais, Brasil 


\section{INTRODUÇÃO}

O Brasil apresenta grande competitividade no mercado de produtos florestais, em razão de suas características edafoclimáticas e do desenvolvimento tecnológico obtido na área de silvicultura (JUVENAL; MATTOS, 2002). Contudo, o país ainda apresenta uma demanda acentuada pela matéria-prima madeira, fazendo com que se tornem essenciais novas pesquisas com diferentes tipos de espécies.

No entanto, boa parte dos estudos silviculturais no Brasil têm se voltado para as espécies de rápido crescimento do gênero Eucalyptus e Pinus. De acordo com Moretti et al. (20II) outras espécies devem ser estudadas visando uma maior diversificação no tocante à produção florestal, obtendo assim novas opções de madeira tecnologicamente interessantes.

Uma espécie que tem ganhado destaque é o Cedro australiano (Toona ciliata M. Roem var. australis). Pertencente à família Meliaceae é uma espécie originária das regióes tropicais da Austrália que se adaptou muito bem ao Brasil, onde encontrou excelentes condições para o seu desenvolvimento, principalmente no sul da Bahia e em toda a Região Sudeste (ALMEIDA et al., 20 I2; PINHEIRO et al., 2003). Essa espécie apresenta rápido crescimento, chegando a atingir $8 \mathrm{~m}$ de altura e $15 \mathrm{~cm}$ de diâmetro com três anos de idade (PINHEIRO et al., 1994), proporcionando, assim, um bom retorno financeiro em curto espaço de tempo, quando comparado aos cedros nativos e a outras espécies florestais, inclusive o mogno (NASSUR et al., 2013).

O cedro australiano fornece madeira de boa qualidade para marcenaria e construção civil, por isso vem sendo bastante plantado visando à produção de madeira serrada. Podendo ser também utilizado para arborização em parques e jardins, na produção de lâminas e compensados decorativos, construção de barcos e na indústria de móveis (NISGOSKI et al., 20I I).

No entanto, estudos sobre suas características tecnológicas são ainda relativamente escassos, principalmente quando se refere àintrodução dessa espécie nos reflorestamentos em nosso país, em diferentes idades e locais de crescimento (RIBEIRO et al., 20I la).

Nesse sentido, objetivou-se, neste trabalho avaliar a retratibilidade, nos sentidos base-topo e medulacasca, da madeira de Cedro australiano proveniente de três municípios do Sul do estado de Minas Gerais. Além de verificar a variação na constituição química da madeira, em decorrência da localidade de plantio.

\section{MATERIAL E MÉTODOS}

\section{Amostragem}

O estudo foi realizado com a madeira de cedro australiano com quatro anos de idade plantados em três municípios da região sul do estado de Minas Gerais (Campo Belo, Cana Verde e Santo Antônio do Amparo). Em cada região, foram coletadas cinco árvores. As três localidades estão dentro de um raio de $40 \mathrm{~km}$, com um clima tropical de altitude (CWA), de Koppen, com verões úmidos e invernos secos, precipitação pluviométrica anual de $1250 \mathrm{~mm}$ e temperatura média em torno de $23,5^{\circ} \mathrm{C}$. O solo é do tipo Latossolo Vermelho Escuro. As coordenadas das áreas de plantio são, respectivamente, de $20^{\circ} 5 \mathrm{l}$ ' $55^{\prime \prime} \mathrm{S}$ e 45 $16^{\prime}$ ' 2" O e altitude de $945 \mathrm{~m}$ para Campo Belo;

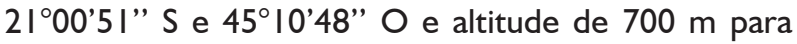

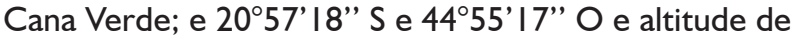
I.020 m para Santo Antônio do Amparo. Para os três plantios, o espaçamento foi de $3 \times 2 \mathrm{~m}$, tendo havido desrama no segundo ano e não foi informado nenhum tipo de adubação.

Após seleção, as árvores foram abatidas e seccionadas, tendo sido retirados discos de quatro centímetros de espessura na base e a cada I,30 m do seu comprimento. $\mathrm{O}$ número de discos por árvore variou conforme a altura das mesmas, tendo o último disco sido retirado antes da primeira bifurcação do fuste (Figura I).

\section{Determinação dos componentes químicos da madeira}

Os discos obtidos foram, então, transformados em quatro cunhas, das quais uma delas foi utilizada na determinação dos principais componentes químicos da madeira de Cedro australiano (Figura I). Sendo a análise química realizada por árvore, para cada localidade. Foram determinados os teores de extrativos totais (ASSOCIAÇÃO BRASILEIRA DE NORMAS TÉCNICAS - ABNT, 20I0b), teor de lignina (ABNT, 20I0a), teor de cinzas (ABNT, 2003b) e holocelulose (obtida pela diferença $H(\%)=100-\%$ Extrativos totais - \%Teor de lignina).

\section{Avaliação da retratibilidade e da densidade básica}

Para a determinação das retratibilidades e do coeficiente de anisotropia foram selecionadas duas cunhas opostas a cada altura (Figura I). De cada cunha 


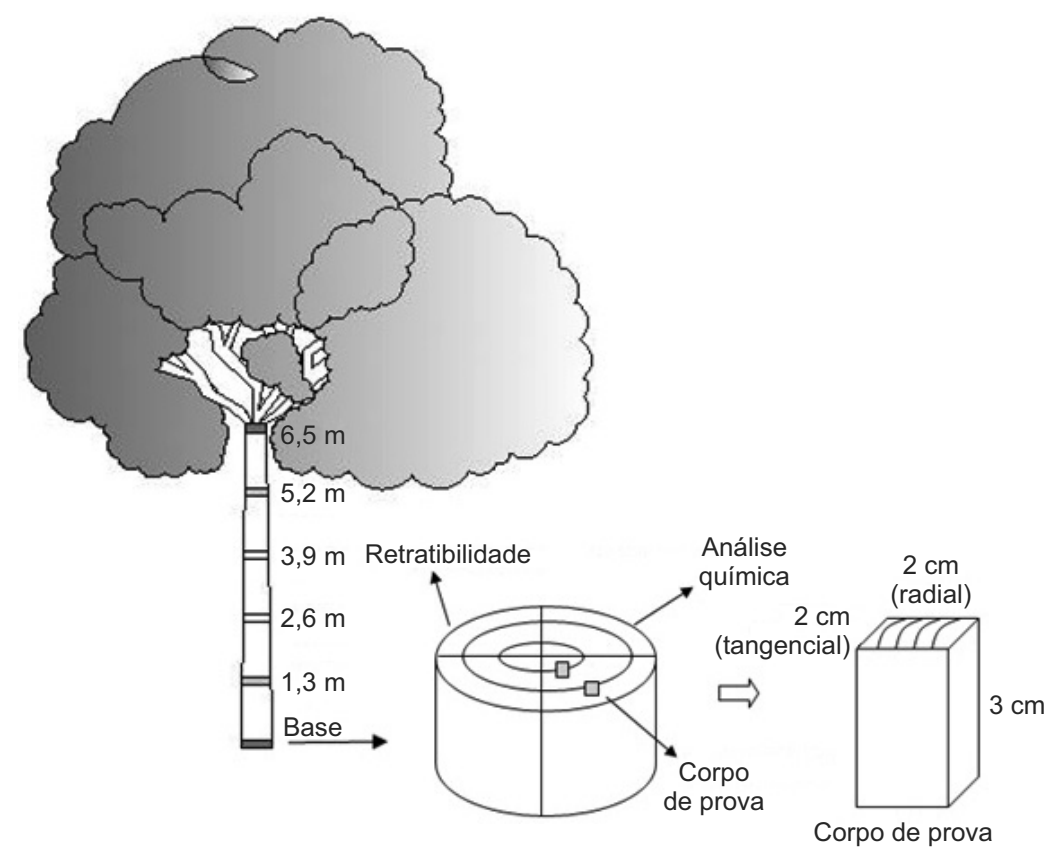

FIGURA I Esquema de retirada das amostras.

FIGURE I Scheme of samples withdrawal.

foram retiradas duas amostras, uma em posição interna (mais próxima à medula) e a outra na região externa (presença de alburno, mais próxima da casca), a fim de se avaliar a retratibilidade da espécie nos sentidos medulacasca e base-topo.

A densidade básica média para cada localidade foi determinada de acordo com a norma NBR II94I (ABNT, 2003a). As retratibilidades (tangencial, radial, longitudinal e volumétrica) e o coeficiente de anisotropia (contrações tangencial / contrações radial) foram determinados de acordo com a NBR 7190 (ABNT, 1997).

\section{Análise estatística}

Para a avaliação dos resultados, realizou-se uma análise de variância e teste de médias de Tukey ( $\alpha=1 \%$ e $5 \%$ ) para a análise química da madeira e também para as retratibilidades e coeficiente de anisotropia entre as localidades estudadas. Além ainda da avaliação das retratibilidades e do coeficiente de anisotropia nos sentidos medula-casca e base-topo, dentro de cada localidade.

Aliado a essa análise, foi realizado no sentido medula-casca ajustes de modelos de regressão polinomial para cada posição em função da altura dos discos em relação à base, para cada um dos locais de coleta (Campo Belo, Cana verde e Santo Antônio do Amparo). A análise conjunta dos locais ficou impossibilitada em razão da heterogeneidade de variâncias (heterocedasticidade).
O ajuste dos modelos foi feito no programa estatístico Statistical Analyses System (STATISTICAL ANALYSES SYSTEM INSTITUTE - SAS INSTITUTE, 1999). Foram testados modelos polinomiais de $1^{\circ}, 2^{\circ}$ e $3^{\circ}$ graus, sendo avaliada a significância dos parâmetros de regressão ( $\beta 0$, $\beta 1, \beta 2$ e $\beta 3)$ e o coeficiente de determinação $\left(R^{2}\right)$ do modelo ajustado.

\section{RESULTADOS E DISCUSSÃO}

\section{Constituição química da madeira}

Os valores médios obtidos para a constituição química da madeira de Cedro australiano, nas três localidades avaliadas, estão apresentados na Tabela I.

TABELA I Constituição química da madeira de cedro australiano.

TABLE I Chemical constitution of Australian cedar wood.

\begin{tabular}{lcccc}
\hline \multirow{2}{*}{ Localidade } & \multicolumn{4}{c}{ Constituição química (\%) } \\
\cline { 2 - 5 } & Holocelulose & Lignina & Extrativos & Cinzas \\
\hline Campo Belo & 66,01 a & 20,46 a & 12,81 a & 0,91 a \\
Cana Verde & 62,58 a & 19,90 a & 16,88 a & 0,81 a \\
$\begin{array}{l}\text { Santo Antônio } \\
\text { do Amparo }\end{array}$ & 63,79 a & 20,57 a & 14,77 a & 0,95 a \\
\hline Média geral & 64,13 & 20,31 & 14,82 & 0,89 \\
\hline
\end{tabular}

Médias seguidas da mesma letra, não diferem entre si, pelo teste de Tukey a $1 \%$ de significância. 
Não foi observada diferença significativa entre os constituintes químicos da madeira de cedro australiano nas diferentes localidades. Porém, quando comparado com os valores médios encontrados em literatura, foi verificado que a madeira de Cedro australiano, aos quatro anos de idade, apresentou valor médio de holocelulose (celulose + hemiceluloses) inferior ao encontrado por Trianoski (2010), o qual obteve o valor médio de $70,36 \%$ para a mesma espécie aos 17 anos de idade. Provavelmente, tal diferença é decorrente da menor porcentagem de celulose presente na madeira juvenil em relação à madeira adulta, conforme citado por Klock et al. (2005).

Quanto aos teores de lignina insolúvel obtidos nas três localidades avaliadas, estes foram inferiores aos encontrados na literatura para madeiras de folhosas. Por exemplo, Caixeta e Pastore (2007), estudando a composição química da madeira de mogno (Swietenia macrophylla, King), encontraram 30,52\% de lignina insolúvel. Enquanto que Mori, F. et al. (2003), estudando espécies de eucaliptos no armazenamento da aguardente de cana-de açúcar, obtiveram teores médios de lignina de $24,97 \%$ à $35,50 \%$ para as espécies Eucalyptus dunii e Eucalyptus resinifera, respectivamente.

O valor médio obtido para os extrativos foi de $14,84 \%$, esse resultado é bastante significativo, visto que madeiras de folhosas apresentam em média de $2 \%$ a $3 \%$ de extrativos (KLOCK et al., 2005). Apesar disso, Trianoski (2010) também obteve valor médio elevado de extrativos para a madeira de Cedro australiano, sendo esse valor de 10,33\% para a espécie aos 17 anos de idade. Essa maior quantidade de extrativos para a madeira de Cedro australiano pode proporcionar maior resistência natural da madeira, visto que parte dos extrativos é de origem fenólica, vindo, assim, a apresentar propriedades fungicidas e inseticidas (LEPAGE, 1986). Contudo, em alguns casos pode vir a ocasionar dificuldade na colagem da madeira.

O teor de cinzas obtido foi inferior a 1\% para as três localidades. Segundo Mori, C. et al. (2003) baixos valores desse componente na madeira fazem com que ocorram menores desgastes de facas e serras durante o seu processamento. Os autores salientaram ainda que o teor de cinzas está diretamente relacionado ao sítio de crescimento da árvore.

\section{Retratibilidade e coeficiente de anisotropia para cada localidade}

Os valores médios obtidos para a densidade básica (DB), retratibilidade tangencial (Tang.), radial
(Rad.), longitudinal (Long.) e volumétrica (Volum.), e ainda o coeficiente de anisotropia (CA), estão apresentados na Tabela 2.

TABELA 2 Valores médios de densidade, retratibilidade e coeficiente de anisotropia.

TABLE 2 Mean values of density, shrinkage and coefficient of anisotropy.

\begin{tabular}{lcccccc}
\hline \multirow{2}{*}{ Localidade } & \multirow{2}{*}{$(\mathrm{DB}$} & \multicolumn{4}{c}{ Retratibilidade (\%) } & CA \\
\cline { 3 - 5 } & $\left(\mathrm{g} \cdot \mathrm{cm}^{-3}\right)$ & Tang. & Rad. & Long. Volum. & \\
\hline Campo Belo & 0,310 & 7,23 a & 2,65 a & 0,70 a & 14,23 a & 2,73 a \\
Cana Verde & 0,318 & 7,10 a & 2,69 a & 0,65 a & 14,68 a & 2,64 a \\
$\begin{array}{l}\text { Santo Antônio } \\
\text { do Amparo }\end{array}$ & 0,285 & 9,70 b & 3,05 b & 0,79 a & 18,06 b & 3,18 b \\
\hline Média geral & 0,304 & 8,01 & 2,80 & 0,71 & 15,65 & 2,85 \\
\hline
\end{tabular}

Médias seguidas da mesma letra, não diferem entre si, pelo teste de Tukey a 5\% de significância.

Observou-se que houve diferença estatística apenas para a localidade de Santo Antônio do Amparo, sendo obtidos para essa localidade maiores valores médios de retratibilidade tangencial, radial e volumétrica. Além, ainda, de um maior coeficiente de anisotropia.

Como não foi observada diferença significativa entre os constituintes químicos da madeira, pode-se inferir que essa relação deve estar associada à questão da diferença anatômica da madeira nas diferentes localidades. Ribeiro et al. (20l lb), avaliando as características anatômicas da madeira de Cedro australiano, nas mesmas localidades desse estudo, e também quando o plantio apresentava-se com 4 anos de idade, observou diferença significativas entre as localidades, quanto à espessura da parede, ângulo microfibrilar, diâmetro de lume e comprimento da fibra, sendo que no plantio de Santo A. do Amparo foi observada maior espessura da parede das fibras, o que pode ter ocasionado os maiores valores de retração. Porém, apesar da maior espessura da parede, a madeira desse plantio apresentou o menor valor médio para a densidade básica (Tabela 2), o que pode estar relacionado com as proporções dos tipos de células, como por exemplo, uma maior porcentagem de parênquima.

Contudo, apesar dessa diferenciação estatística quanto às retrações, quando comparado a média geral por localidade, das contrações tangencial, radial, longitudinal, volumétrica e do coeficiente de anisotropia com outras espécies madeireiras, pode-se observar que as contrações lineares e volumétricas na madeira de Cedro australiano das três localidades são coerentes com aquelas utilizadas no mercado de madeiras (Tabela 3). No entanto, o coeficiente de anisotropia apresentou- 
TABELA 3 Comparação com os valores de retratibilidade e coeficiente de anisotropia encontrados em literatura.

TABLE 3 Comparison with the values of shrinkage and coefficient of anisotropy found in the literature.

\begin{tabular}{|c|c|c|c|c|c|}
\hline \multirow{2}{*}{ Localidade } & \multicolumn{4}{|c|}{ Retratibilidade (\%) } & \multirow{2}{*}{ CA } \\
\hline & Tangencial & Radial & Longitudinal & Volumétrica & \\
\hline Toona Ciliata - Campo Belo & 7,23 & 2,65 & 0,70 & 14,23 & 2,73 \\
\hline Toona Ciliata - Cana Verde & 7,10 & 2,69 & 0,65 & 14,68 & 2,64 \\
\hline Toona Ciliata - Santo Antônio do Amparo & 9,70 & 3,05 & 0,79 & 18,06 & 3,18 \\
\hline Swietenia Macrophylla' (Mogno) & 4,70 & 2,90 & * & 7,20 & 1,62 \\
\hline Cedrela odorata' (Cedro) & 12,10 & 9,06 & * & 20,82 & $\mathrm{I}, 34$ \\
\hline Eucalyptus saligna ${ }^{2}$ & 14,83 & 7,67 & * & 26,0 & 1,99 \\
\hline
\end{tabular}

*Valores não significativos; ' Instituto Brasileiro do Meio Ambiente e dos Recursos Naturais Renováveis - IBAMA (20I I); ${ }^{2}$ Oliveira e Silva (2003).

se com valores mais elevados, podendo estar associado ao fato da madeira ainda ser juvenil, o que demonstra a necessidade de mais estudos quanto às características da madeira do Cedro australiano em idades mais avançadas, visando, assim, a avaliar o seu comportamento com o passar do tempo de plantio e consequentemente com as mudanças anatômicas.

\section{Variação da retratibilidade e do coeficiente de anisotropia no sentido medula-casca e base- topo}

\section{Campo Belo}

De acordo com os resultados da análise de variância, foi observado efeito significativo da variação da retratibilidade da madeira de Cedro australiano, no sentido base-topo, apenas sobre as contrações lineares tangencias e contração volumétrica (Tabela 4). Enquanto que no sentido medula-casca não foi observada nenhuma variação significativa. Esse resultado é desejável em termos de transformação primária da madeira, visto que diferenças de propriedades no sentido transversal tornam o desdobro das toras mais complexo.

TABELA 4 Valores médios da contração tangencial e volumétrica no sentido base-topo.

TABLE 4 Mean values of tangential and volumetric contraction in bottom-up direction.

\begin{tabular}{ccc}
\hline Altura $(\mathrm{m})$ & $\begin{array}{c}\text { Contração } \\
\text { tangencial (\%) }\end{array}$ & $\begin{array}{c}\text { Contração } \\
\text { volumétrica (\%) }\end{array}$ \\
\hline 5,2 & $4,35 \mathrm{a}$ & $19,80 \mathrm{a}$ \\
3,9 & $5,16 \mathrm{ab}$ & $16,67 \mathrm{ab}$ \\
2,6 & $6,10 \mathrm{abc}$ & $12,30 \mathrm{ab}$ \\
1,3 & $9,18 \mathrm{c}$ & $12,00 \mathrm{ab}$ \\
0 & $8,27 \mathrm{bc}$ & $10,40 \mathrm{~b}$ \\
\hline
\end{tabular}

Médias seguidas da mesma letra, não diferem entre si, pelo teste de Tukey a $5 \%$ de significância.
Os resultados revelam que até $2,6 \mathrm{~m}$ de altura não existe diferença estatística em relação à base quanto à retração tangencial, sendo que, a essa altura, até $5,2 \mathrm{~m}$ (topo), também não foi observada diferença significativa, o que nos permite concluir que a árvore em questão de contração tangencial no sentido basetopo pode ser dividida em duas partes diferentes. Já, em relação à contração volumétrica, foi observada diferença significativa apenas entre a base das árvores e a altura de 5,2 m, sendo que, com o aumento da altura, observa-se a tendência de aumento da retração volumétrica da madeira.

Apesar de não ser observada diferença estatística significativa da retratibilidade e do coeficiente de anisotropia no sentido medula-casca foi observada relação entre a retratibilidade e coeficiente de anisotropia de cada posição no sentido medula-casca (interna e externa) com o aumento da altura da árvore (base-topo) (Figura 2).

Pela análise dos gráficos, observa-se que, de forma geral, quando analisadas as amostras mais próximas da casca, as retrações tendem a diminuir com a altura da árvore. Enquanto que as amostras mais próximas da medula apresentam comportamento diferenciado para cada um dos tipos de retrações, sendo que para a retração tangencial e volumétrica tendem a diminuir com a altura, para a retração longitudinal tende a crescer até a altura de 2,6 $\mathrm{m}$ e depois decresce novamente; e para a retração radial decresce até $2,6 \mathrm{~m}$ e cresce novamente. Para o coeficiente de anisotropia também foi observado comportamento diferente quanto às amostras mais próximas a medula e mais próximas a casca, tendo essas variações opostas com o aumento da altura da árvore.

Quanto aos ajustes dos polinômios, em todos os casos foi observado coeficiente de determinação $\left(R^{2}\right)$ relativamente alto. Sendo os polinômios de segundo grau mais apropriados para a determinação 

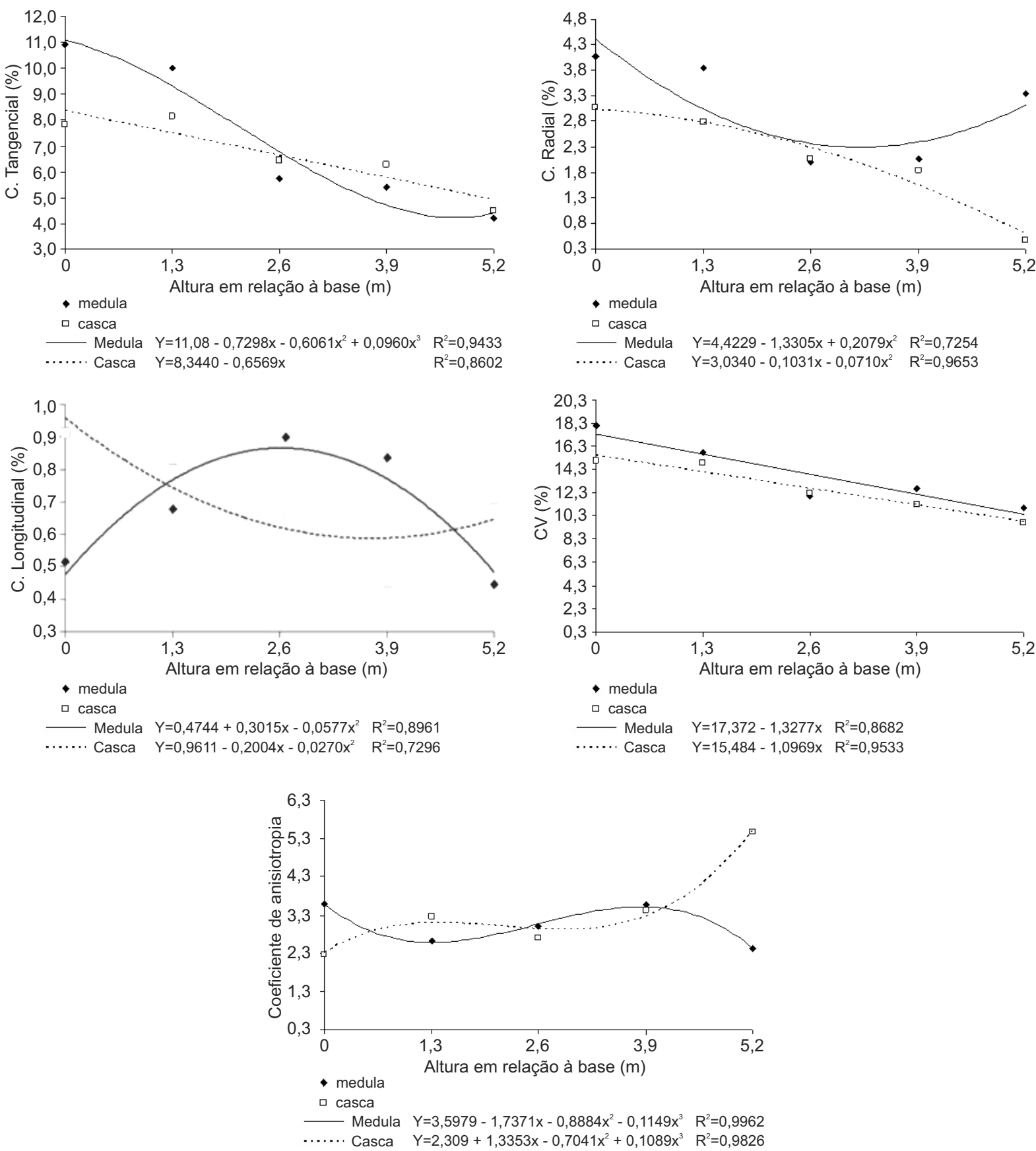

FIGURA 2 Variação dos valores médios de retratibilidade e coeficiente de anisotropia para cada posição no sentido medula-casca em relação à altura da árvore.

FIGURE 2 Variation of the average values of shrinkage and anisotropy coefficient for each position in the pith-bark direction in relation to tree height.

das retrações radiais e longitudinais das amostras próximas da medula ou próxima a casca. Para a retração volumétrica, o polinômio de primeiro grau se mostrou com os melhores resultados, o mesmo aconteceu para as retrações tangenciais das amostras próximas a casca. Enquanto que para as retrações tangenciais das amostras próximas a medula e também para o coeficiente de anisotropia, os polinômios de terceiro grau foram os mais adequados.

\section{Cana Verde}

De acordo com os resultados da análise de variância, foi observado efeito significativo da variação 
da retratibilidade da madeira de Cedro australiano, no sentido base-topo, apenas sobre as contrações lineares tangencias e contrações volumétricas (Tabela 5). Enquanto que no sentido medula-casca foi observada variação significativa apenas para as contrações radiais e coeficiente de anisotropia (Tabela 6).

TABELA 5 Valores médios da contração tangencial e volumétrica no sentido base-topo.

TABLE 5 Mean values of tangential and volumetric contraction in bottom-up direction.

\begin{tabular}{ccc}
\hline Altura $(\mathrm{m})$ & $\begin{array}{c}\text { Contração } \\
\text { tangencial }(\%)\end{array}$ & $\begin{array}{c}\text { Contração } \\
\text { volumétrica }(\%)\end{array}$ \\
\hline 6,5 & $5,46 \mathrm{a}$ & $12,50 \mathrm{a}$ \\
5,2 & $5,53 \mathrm{a}$ & $13,30 \mathrm{a}$ \\
3,9 & $5,79 \mathrm{a}$ & $13,50 \mathrm{a}$ \\
2,6 & $5,64 \mathrm{a}$ & $13,83 \mathrm{a}$ \\
1,3 & $7,26 \mathrm{a}$ & $15,60 \mathrm{a}$ \\
0 & $11,82 \mathrm{~b}$ & $19,37 \mathrm{~b}$ \\
\hline
\end{tabular}

Médias seguidas da mesma letra, não diferem entre si, pelo teste de Tukey a 5\% de significância.

TABELA 6 Valores médios da contração radial no sentido medula-casca.

TABLE 6 Mean values of radial contraction in the pith-bark direction.

\begin{tabular}{ccc}
\hline Posição & $\begin{array}{c}\text { Contração } \\
\text { radial (\%) }\end{array}$ & $\begin{array}{c}\text { Coeficiente de } \\
\text { anisotropia }\end{array}$ \\
\hline Interna & $3,26 \mathrm{a}$ & $2,63 \mathrm{a}$ \\
Externa & $2,12 \mathrm{~b}$ & $4,18 \mathrm{~b}$ \\
\hline
\end{tabular}

Médias seguidas da mesma letra, não diferem entre si, pelo teste de Tukey a 5\% de significância.

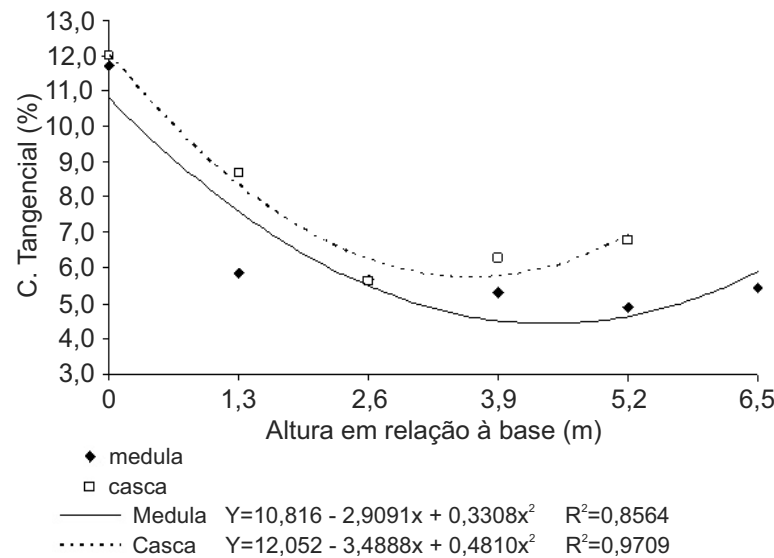

Tanto nas contrações tangenciais como na volumétrica no sentido base-topo, houve diferença estatística apenas da base em relação às outras alturas de amostragem, as quais foram iguais estatisticamente. Sendo que tal fato pode estar associado a uma provável maior espessura da parede celular na base dos troncos das árvores.

Enquanto que para as contrações radiais e coeficiente de anisotropia no sentido medula-casca (Tabela 6), a posição interna apresentou menor estabilidade dimensional que a posição externa, o que pode estar relacionado ao fato da madeira mais próxima da medula apresentar maior ângulo microfibrilar (KLOCK et al., 2005), contudo apresentou também o menor coeficiente de anisotropia.

$\mathrm{Na}$ Figura 3, estão apresentadas as retrações lineares e volumétricas e o coeficiente de anisotropia para cada posição no sentido medula-casca (interna e externa) com o aumento da altura da árvore (basetopo).

Pela análise dos gráficos, observa-se que, de forma geral, quando analisadas as amostras mais próximas da medula, as retrações tendem a diminuir com a altura da árvore até a altura de 5,2 m, com certa tendência de aumento após esta altura. Para as amostras mais próximas da medula, o comportamento foi o mesmo das amostras próximas as casca quando analisada a retração tangencial, enquanto que para as demais retrações a tendência foi de aumento até a altura de $1,3 \mathrm{~m}$, seguido do decréscimo com o aumento da altura até $5,2 \mathrm{~m}$ e, então, com o aumento novamente. Para o coeficiente de anisotropia também foi observado comportamento diferente quanto

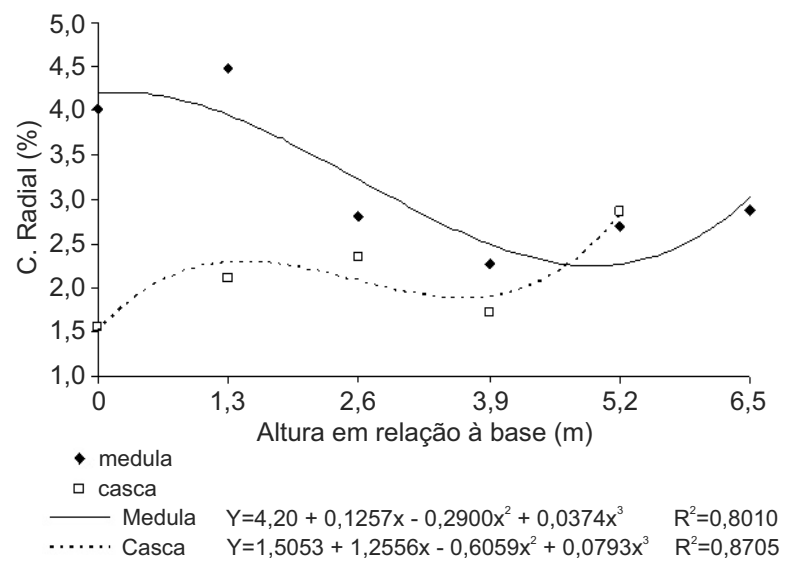

FIGURA 3 Variação dos valores médios de retratibilidade e coeficiente de anisotropia para cada posição no sentido medula-casca em relação à altura da árvore.

FIGURE 3 Variation of the average values of shrinkage and anisotropy coefficient for each position in the pith-bark direction in relation to tree height.

Continua...

To be continued... 
FIGURA 3 Continuação...

FIGURE 3 Continued...

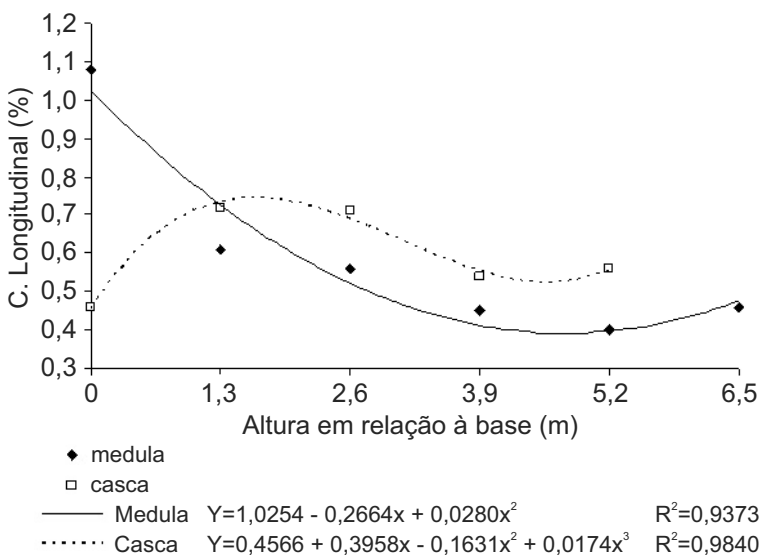

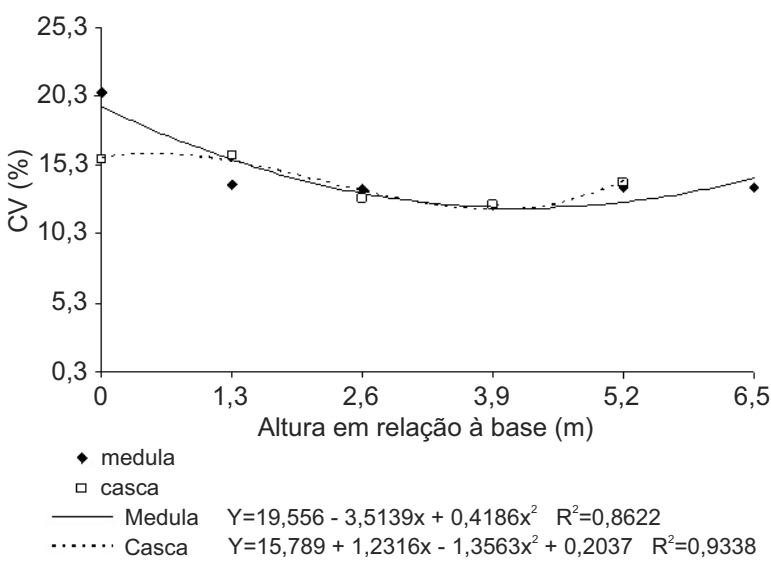

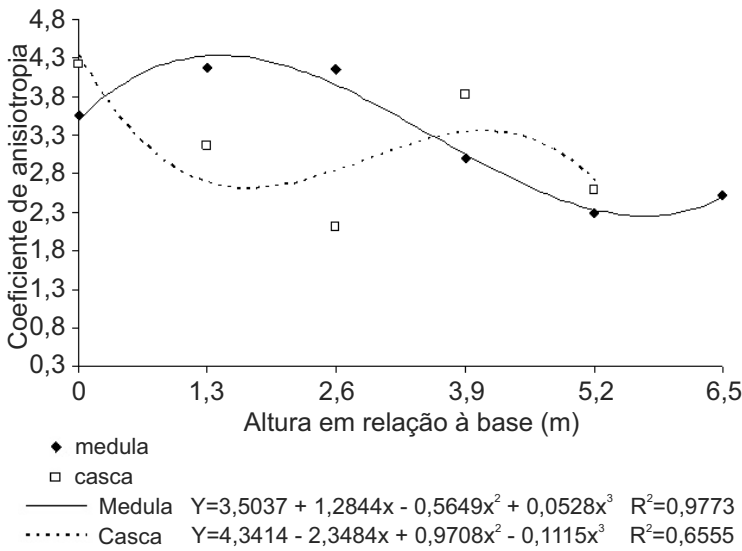

às amostras mais próximas à medula e mais próximas à casca, tendo essas variações opostas com o aumento da altura da árvore, assim como o observado na localidade de Campo Belo.

Quanto aos ajustes dos polinômios, em todos os casos foi observado coeficiente de determinação $\left(\mathrm{R}^{2}\right)$ relativamente alto. Sendo os polinômios de terceiro grau mais apropriados para a determinação das retrações radias e das amostras mais próximas a casca nas retrações volumétrica e longitudinal, assim como na determinação do coeficiente de anisotropia. Enquanto que os polinômios de segundo grau foram os mais apropriados para as outras retrações.

\section{Santo Antônio do Amparo}

De acordo com os resultados da análise de variância, foi observado efeito significativo da variação da retratibilidade da madeira de Cedro australiano, no sentido base-topo, apenas sobre as contrações lineares tangencias (Tabela 7). Enquanto que no sentido medulacasca não foi observada nenhuma variação significativa.
Observa-se que, para as contrações tangenciais no sentido base-topo, houve diferença estatística da base em relação às outras alturas de amostragem. Sendo que tal fato, assim como o discutido para a localidade de Cana Verde, pode estar associado a uma provável maior espessura da parede celular na base dos troncos das árvores. Ainda em relação à contração tangencial, o menor valor foi obtido na região de I,30 m de altura $(6,79 \%)$, porém da altura de $1,3 \mathrm{~m}$ até $3,9 \mathrm{~m}$ não houve diferença significativa.

TABELA 7 Valores médios da contração tangencial no sentido base-topo.

TABLE 7 Mean values of tangential contraction in bottomup direction.

\begin{tabular}{cc}
\hline Altura $(\mathrm{m})$ & Contração tangencial (\%) \\
\hline 5,2 & $10,07 \mathrm{~b}$ \\
3,9 & $8,80 \mathrm{ab}$ \\
2,6 & $7,18 \mathrm{ab}$ \\
1,3 & $6,79 \mathrm{a}$ \\
0 & $12,50 \mathrm{c}$ \\
\hline
\end{tabular}

Médias seguidas da mesma letra, não diferem entre si, pelo teste de Tukey a 5\% de significância. 
Apesar de não ser observada diferença estatística da retratibilidade e do coeficiente de anisotropia no sentido medula-casca foi observada relação entre a retratibilidade e coeficiente de anisotropia de cada posição no sentido medula-casca (interna e externa) com o aumento da altura da árvore (base-topo) (Figura 4).

Pela análise dos gráficos, observa-se para as amostras mais próximas da casca, que existe uma
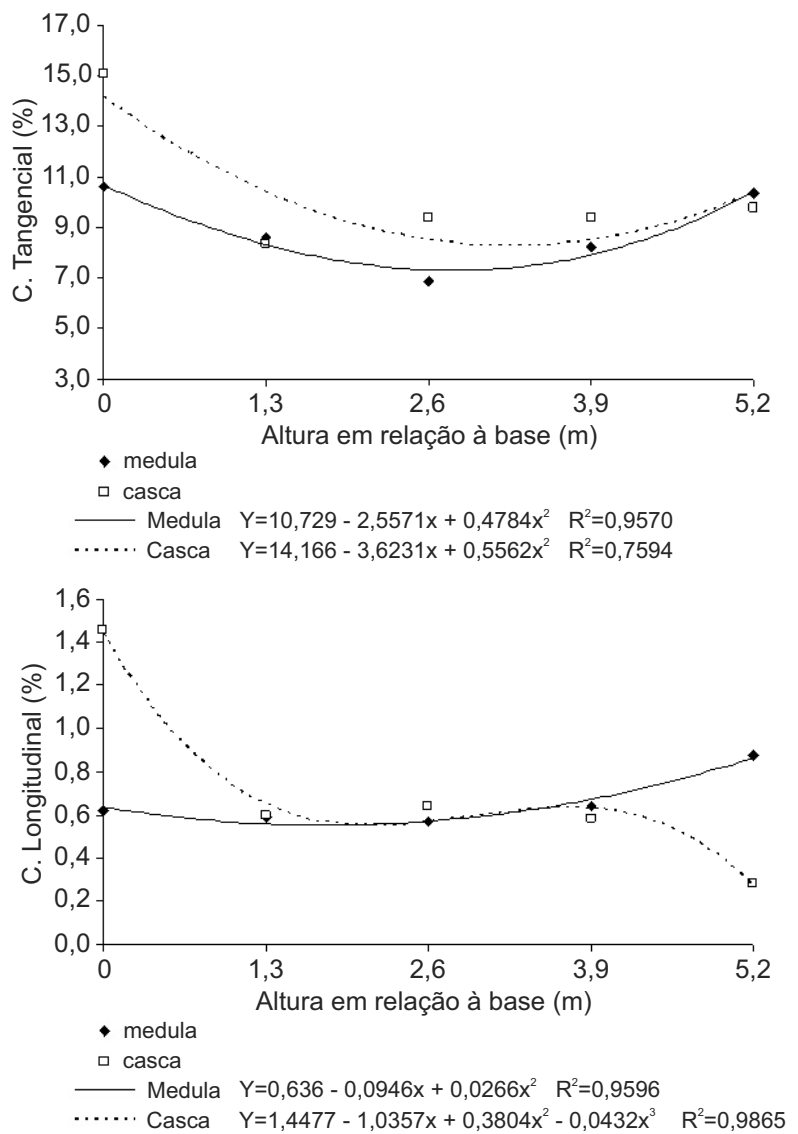

tendência de diminuição das retrações tangenciais e longitudinais e também do coeficiente de anisotropia com o aumento da altura da árvore. Já, para a contração radial e volumétrica existe uma tendência de diminuição até a altura de I,3 $\mathrm{m}$, seguido do aumento da retração com o aumento da altura de amostragem.

Para as amostras mais próximas da medula, não houve tendência significativa para a contração volumétrica
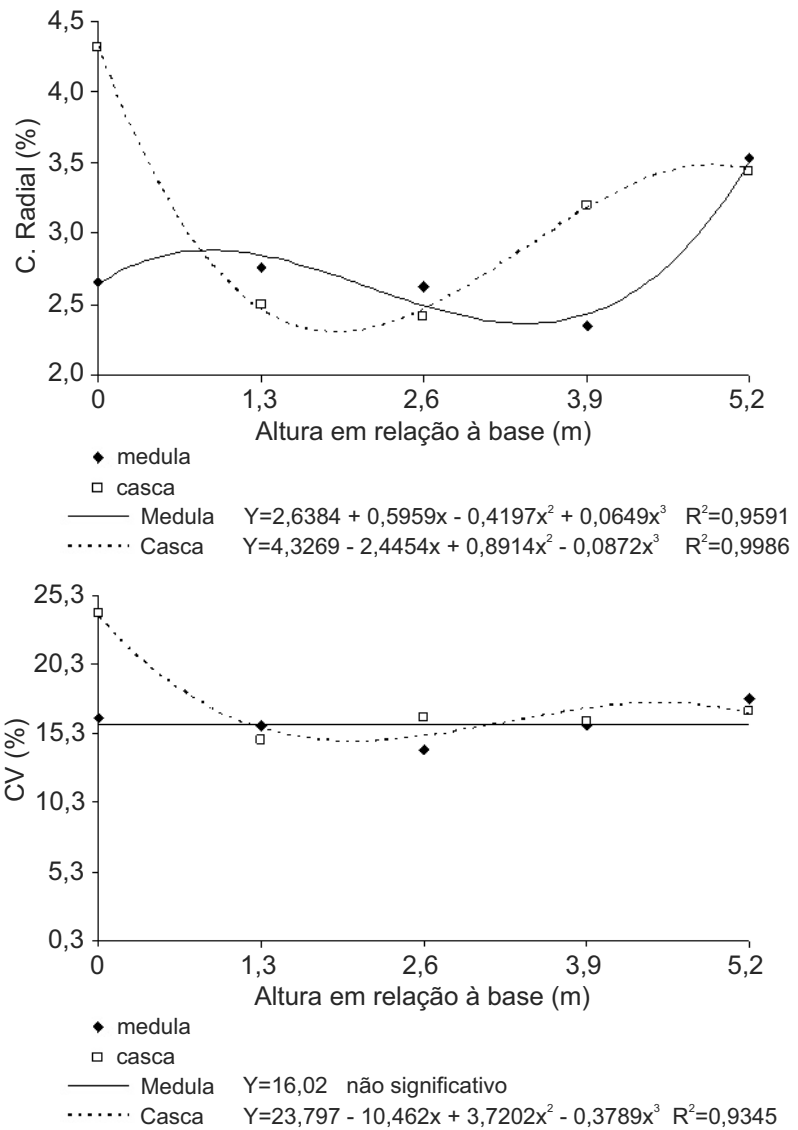

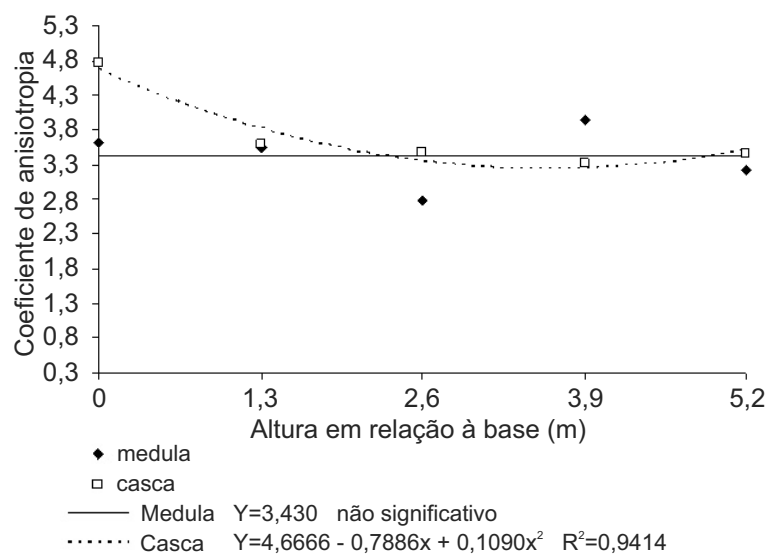

FIGURA 4 Variação dos valores médios de retratibilidade e coeficiente de anisotropia para cada posição no sentido medula-casca em relação à altura da árvore.

FIGURE 4 Variation of the average values of shrinkage and anisotropy coefficient for each position in the pith-bark direction in relation to tree height. 
e para o coeficiente de anisotropia. $\mathrm{Na}$ contração radial, ocorreu o aumento até a altura de I, $3 \mathrm{~m}$, seguido de uma queda até $3,9 \mathrm{~m}$ de altura da árvore e então do aumento até $\circ$ topo. Para as contrações tangencial e longitudinal houve uma tendência de diminuição até a altura de 2,6 m, seguido do aumento até o topo da árvore.

Quanto aos ajustes dos polinômios, não foi possível o ajuste para a contração volumétrica e coeficiente de anisotropia quando analisadas as amostras mais próximas da medula (Região interna). Nos demais casos, foram observados coeficientes de determinação $\left(R^{2}\right)$ relativamente altos. O polinômio de terceiro grau se mostrou mais apropriado para a determinação das retrações radiais (interna e externa) e das retrações longitudinal (externa) e volumétrica (externa). O polinômio de segundo grau se mostrou mais apropriado para as retrações tangenciais (interna e externa), para a retração longitudinal (Interna) e o coeficiente de anisotropia (externa).

\section{CONCLUSÕES}

Não foi observada variação significativa dos teores de holocelulose, lignina, extrativos e cinzas entre as três localidades de plantios avaliadas.

Houve efeito da localidade sobre as retrações avaliadas, sendo o plantio de Santo Antônio do Amparo o que apresentou os maiores valores médios de retrações tangencial, radial e volumétrica, além ainda dos maiores valores de coeficiente de anisotropia.

$\mathrm{Na}$ direção base-topo, não houve variação significativa das contrações radial e longitudinal para as três localidades avaliadas. Contudo, foi observada variação significativa para as contrações tangencial e volumétrica para as localidades de Campo Belo e Cana Verde, e variação significativa da contração tangencial para o plantio de Santo Antônio do Amparo.

$\mathrm{Na}$ direção medula-casca, foi observada variação significativa apenas da contração radial e do coeficiente de anisotropia para a localidade de Cana Verde.

Apesar da diferenciação medula-casca ser significativa apenas para o plantio de Cana Verde, nas três localidades quando avaliada a variação da retratibilidade no sentido base-topo das amostras mais internas e mais externas de forma separada, observaram-se padrões de variações diferentes para as duas amostras, sendo esses padrões bastante variáveis nos diferentes tipos de retração e também para o coeficiente de anisotropia. Contudo, a utilização de polinômios para a determinação dessas variações se mostrou bastante adequado na maioria dos casos, obtendo, assim, coeficientes de determinação relativamente elevados.

\section{AGRADECIMENTOS}

À Fapemig e ao CNPQ, pelo apoio financeiro e pela concessão de bolsas.

\section{REFERÊNCIAS}

ALMEIDA, N. A.; MENDES, L. M.; OKINO, E. Y. A.; GARLET, A.; MORI, F. A.; MENDES, R. F. Biodegradação de produdos à base da madeira de cedro australiano (Toona ciliata M. Roem. var. australis). Cerne, Lavras, v. 18, n. I, p. 17-26, jan./mar. 2012.

ASSOCIAÇÃO BRASILEIRA DE NORMAS TECNICAS. NBR 7190: projeto de estruturas da madeira. Rio de Janeiro, 1997. $107 \mathrm{p}$.

ASSOCIAÇÃO BRASILEIRA DE NORMAS TÉCNICAS. NBR 7989: pasta celulósica e madeira: determinação de lignina insolúvel em ácido. Rio de Janeiro, 2010a. 6 p.

ASSOCIAÇÃO BRASILEIRA DE NORMAS TÉCNICAS. NBR | | 94 |: determinação da densidade básica em madeira. Rio de Janeiro, 2003a. 6 p.

ASSOCIAÇÃO BRASILEIRA DE NORMAS TÉCNICAS. NBR 13999: papel, cartão, pastas celulósicas e madeira: determinação do resíduo (cinza) após a incineração a $525^{\circ} \mathrm{C}$. Rio de Janeiro, 2003b. $4 \mathrm{p}$.

ASSOCIAÇÃO BRASILEIRA DE NORMAS TÉCNICAS. NBR 14853: madeira: determinação do material solúvel em etanol-tolueno e em diclorometano e em acetona. Rio de Janeiro, 20I0b. 3 p.

CAIXETA, M. L. L.; PASTORE, T. C. M. Composição química da madeira de mogno (Swietenia macrophylla King). In: REUNIÃO ANUAL DA SOCIEDADE BRASILEIRA DE QUÍMICA, 30., 2007, São Paulo. Anais... São Paulo: Sociedade Brasileira de Química, 2007. I CD-ROM.

INSTITUTO BRASILEIRO DO MEIO AMBIENTE E DOS RECURSOS NATURAIS RENOVÁVEIS. Madeiras brasileiras. Disponível em: < http://www.ibama.gov.br/lpf/ madeira/caracteristicas. php?ID $=59 \&$ caracteristica $=207>$. Acesso em: I4 ago. $201 \mathrm{l}$.

JUVENAL, T. L.; MATTOS, R. L. G. O setor florestal no Brasil e a importância do reflorestamento. BNDES Setorial, Rio de Janeiro, n. 16, p. 3-30, set. 2002.

KLOCK, U.; MUÑIZ, G. I. B.; ANZALDO, J. H.; ANDRADE, A. S. Química da madeira. 3. ed. Curitiba: FUPEF, 2005. 
LEPAGE, E. S. (Coord.). Manual de preservação de madeiras. São Paulo: IPT, I 986. 34 I p.

MORETTI, B. S.; FURTINI NETO, A. E.; PINTO, S. I. C.; FURTINI, I. V.; MAGALHÃES, C. A. S. Crescimento e nutrição mineral de mudas de cedro australiano (Toona ciliata) sob omissão de nutrientes. Cerne, Lavras, v. I7, n. 4, p. 453-463, out./dez. 201 I.

MORI, C. L. S. O.; MORI, F. A.; MENDES, L. M.; SILVA, J. R. M. Caracterização da madeira de Angico Vermelho (Anadenanthera peregrina (Benth) Speng) para confecção de móveis. Revista Brasil Florestal, Brasília, n. 77, p. 29-36, 2003.

MORI, F. A.; MENDES, L. M.; TRUGILHO, P. F.; CARDOSO M. G. Utilização de eucaliptos e madeiras nativas no armazenamento da aguardente de cana-de-açúcar. Ciência e Tecnologia de Alimentos, Campinas, v. 23, n. 3, p. $396-$ 400, set./dez. 2003.

NASSUR, O. A. C.; ROSADO, L. R.; ROSADO, S. C. S.; CARVALHO, P. M. Variações na qualidade de toras de Toona ciliata M. Roem. com dezoito anos de idade. Cerne, Lavras, v. 19, n. I, p. 43-49, jan./mar. 2013.

NISGOSKI, S.; TRIANOSKI, R.; MUNIZ, G. I. B.; MATOS, J. L. M.; BATISTA, F. R. R. Anatomia da madeira de Toona ciliata características das fibras para produção de papel. Floresta, Curitiba, v. 4I, n. 4, p. 7I7-728, out./dez. 2011 .
OLIVEIRA, J. T. S.; SILVA, J. C. Variação radial da retratibilidade e densidade básica da madeira de Eucalyptus saligna Sm. Revista Árvore, Viçosa, v. 27, n. 3, p. 38I-385, 2003.

PINHEIRO, A. L.; LANI, L. L.; COUTO, L. Cultura do cedro australiano para produção de madeira serrada. Viçosa, MG: UFV, 2003. 42 p.

PINHEIRO, A. L.; RAMALHO, R. S.; BARREIROS, H. S. Árvores exóticas em Viçosa: II., Toona ciliata M. Roem. var. australis (F. V. M.) C. DC. (MELIACEAE). Revista Ceres, Viçosa, v. 4I, n. 234, p. I03-II2, 1994.

RIBEIRO, A. O.; MENDES, L. M.; MORI, F. A.; ZIECH, R. Q. S.; MENDES, R. F. Variação da densidade básica da madeira de Toona ciliata Roem cultivada em diferentes localidades. Scientia Forestalis, Piracicaba, v. 39, n. 9I, p. 359-366, set. 201 la.

RIBEIRO, A. O.; MORI, F. A.; MENDES, L. M. Características das dimensões das fibras e análise do ângulo microfibrilar de toona ciliata cultivada em diferentes localidades. Floresta, Curitiba, v. 4I, n. I, p. 47-56, jan./mar. 20 I Ib.

STATISTICAL ANALYSIS SYSTEM INSTITUTE. SAS/STAT user's guide. Version 7.I. Cary, 1999. Software.

TRIANOSKI, R. Avaliação do potencial de espécies florestais alternativas, de rápido crescimento, para produção de painéis de madeira Aglomerada. 2010. 260 f. Dissertação (Mestrado em Engenharia Florestal) Universidade Federal do Paraná, Curitiba, 2010. 
